\title{
Optimizing conditions for the continuous culture of Isochrysis affinis galbana relevant to commercial hatcheries
}

\author{
J. Marchetti ${ }^{a}$, G. Bougaran ${ }^{a}{ }^{*}$, L. Le Dean ${ }^{a}$, C. Mégrier ${ }^{a}$, E. Lukomska ${ }^{a}$, R. Kaas ${ }^{a}$, E. Olivo ${ }^{a}$, R. Baron ${ }^{c}$,
} R. Robert ${ }^{b}$, J.P. Cadoret ${ }^{a}$

\footnotetext{
${ }^{a}$ Ifremer, Laboratoire Physiologie et Biotechnologie des Algues, rue de l'île d'Yeu BP 2110544311 Nantes cedex 3, France

${ }^{b}$ Ifremer, UMR 100 Physiologie et Écophysiologie des Mollusques Marins, Station Expérimentale d'Argenton, Presqu'île du vivier 29840 Argenton en Landunvez, France

${ }^{c}$ Ifremer, Laboratoire Sciences et Technologies des Bioressources Marines, rue de l'île d'Yeu BP 2110544311

Nantes cedex 3, France
}

\author{
*: Corresponding author : Gael Bougaran, Tel.: + 332403741 24; fax: + 33240374073 \\ email address : gael.bougaran@ifremer.fr
}

\section{Abstract:}

Optimal culture conditions were investigated for the continuous culture of Isochrysis affinis galbana (TIso) by assessing the effects of irradiance, temperature, $\mathrm{pH}$ and nitrogen and phosphorus requirements.

Assessment of the growth rate-irradiance relationship in a turbidostat experiment highlighted that an optimum irradiance efficiency for growth $\left(E_{\mu}\right)$ occurred at irradiance much lower than the saturating level. Furthermore, our modeling approach for productivity pointed out that an optimal set of irradiance and dilution rate could be achieved in order to maximize irradiance efficiency.

Optimal conditions for growth were assessed for temperature, $\mathrm{pH}$ and irradiance by means of a factorial design experiment. The resulting model predicted that optimal culture conditions occurred at $\mathrm{pH}=6.8$, irradiance $=780 \mu \mathrm{mol}$ photons $\cdot \mathrm{m}^{-2} \cdot \mathrm{s}^{-1}$ and temperature $=30^{\circ} \mathrm{C}$ and emphasized significant $\mathrm{pH}$-temperature and $\mathrm{pH}$-irradiance interactions on growth.

The critical N:P ratio was shown to be a decreasing function of the growth rate and revealed high requirements of T-Iso for nitrogen relative to phosphorus. Finally, we propose an integrative optimization procedure for the continuous culture of $I$. affinis galbana and outcomes are discussed.

\section{Highlights}

We investigated optimal conditions for Isochrysis affinis galbana (T-Iso). I Irradiance efficiency is optimal for a given set of irradiance and dilution rate. $\mathrm{pH}$-temperature and $\mathrm{pH}$-irradiance interactions occur on growth. We propose an integrative optimization procedure for T-Iso continuous cultures.

Keywords: Isochrysis affinis galbana ; Irradiance efficiency ; Factor interaction ; Nutrient limitation ; Microalgae cultures 


\section{Introduction}

Microalgae are photosynthetic microorganisms that constitute the first link of the aquatic food chain. Due to their biodiversity, microalgae have many potential application, particularly in the areas of pharmaceuticals, cosmetics and energy (Pulz and Gross, 2004; Spolaore et al., 2006; Rosenberg et al., 2008). However, their use as food in aquaculture remains the major reason for their production (Benemann, 1992; Brown, 2002; Pulz and Gross, 2004). Microalgae are mainly used as food for mollusks and zooplankton, but are also used in the nutrition of early-life-stage crustaceans and small fishes (Borowitzka, 1997; Duerr et al., 1998; Brown, 2002). Despite various alternative diets tested, such as concentrated microalgae (McCausland et al., 1999; Robert et al., 2001), yeast (Nell, 2002), bacteria (Douillet and Langdon, 1994) or even lipid-substitution compounds (Coutteau et al., 1996; Knauer and Southgate, 1997), living microalgae remain necessary for production of larval and juvenile bivalves (Robert and Trintignac, 1997). In France, shellfish production is dominated by the Pacific oyster Crassostrea gigas. Because of high inter-annual variations in spatfall (Robert and Gerard, 1999) and an increasing demand for triploid oysters (Nell, 2002), French hatchery spat production of $C$. gigas has regularly increased from $10 \%$ to 20 $25 \%$ over the last decade (Rico-Villa et al., 2008). Currently, batch production of microalgae $\left(<1 \mathrm{~m}^{3}\right)$ is the most widely used method of algal production in hatcheries, but this is expensive and leads to variable microalgal biochemical composition: $30 \%$ of total production costs are related to larval feeding and thus to microalgae cultivation (Coutteau and Sorgeloos, 1992). In addition, live microalgae production is considered to be the major bottleneck in mollusk hatcheries (Fabregas et al., 1986). Optimization of microalgal culture conditions is, therefore, necessary to reduce production costs and meet the demand of hatchery managers for an easy, cheap, reliable method of producing microalgae of high nutritional value (Coutteau and Sorgeloos, 1992).

Continuous culture is an attractive alternative to batch production (Bougaran et al., 2003) as it allows full automation of the microalgae production process, thereby reducing labor costs. Also, it provides a stable quantity and quality of microalgal biomass due to a better control of the growing environment (Borowitzka, 1997). However, appropriate equipment is required (Loubiere et al., 2009) as well as specific knowledge of the microalgae species and their optimal culture conditions.

Numerous studies have shown that the biochemical composition and physiological status of microalgae cells are altered by different environmental factors. According to Tzovenis (2003) and Sukenik and Wahnon (1991), irradiance increases the growth rate of Isochrysis affinis galbana as well as its levels of carbohydrates, DHA and saturated fatty acids, while it reduces lipid content. Increased temperature was reported to reduce carbohydrates in T-Iso and Chaetoceros sp (Renaud et al., 2002) and to increase the carbon quota of Thalassiosira pseudonana (Berges et al., 2002). It is also reported that high $\mathrm{pH}$ leads to increased growth, $\mathrm{CO}_{2}$ uptake and amino acid content in Skeletonema costatum (Taraldsvik and Myklestad, 2000). The factors affecting microalgae cultures include also dilution rate (Sukenik and Wahnon, 1991; Alonso et al., 2000) and culture medium (Fabregas et al., 1995; Sanchez et al., 2000). In the present study, three experiments were designed to find ways of improving Isochrysis affinis galbana (T-Iso) growth and reducing the production costs associated with labor, energy and chemical supplements, which are considered as the greatest expenses for hatcheries (Boeing, 2000). In a first experiment, the relationship between growth rate and irradiance was assessed; irradiance efficiency for T-Iso growth could be computed for an optically clear culture $\left(A_{680}<0.1\right)$. A modeling approach was then used to assess the irradiance efficiency for productivity in a light-limited photobioreactor. We then developed a new experimental device, based on a factorial design approach in order to not only assess the main effects of temperature, irradiance and $\mathrm{pH}$ on growth rate, but also the putative interactions between these factors. To complete our optimization procedure for the culture 
conditions, chemostat experiments were used to further characterize the requirements of TIso for nitrogen and phosphorus over a range of growth rate.

\section{Materials and methods}

\subsection{Microalgal strain}

The prymnesiophyceae Isochrysis affinis galbana was obtained from the Culture Collection of Algae and Protozoa (CCAP 927/14, Scotland). The strain was maintained in the laboratory in a volume of $250 \mathrm{~mL}$. Transfer_was made into $2 \mathrm{~L}$-flasks, 5 to 7 days later, to culture a microalgal population sufficient for the subsequent experiments.

\subsection{Culture medium}

For the experiments and strain maintenance, cultures were grown in $0.22 \mu \mathrm{m}$ filtered sterilized seawater, enriched with the Walne medium (1966), unless otherwise specified.

\subsection{Assessment of cell population and check for steady-state}

Cellular concentration was assessed daily with absorption $A_{680}$ measurements and by image analysis on Malassez slides using specific image analysis software (Samba Technologies, Meylan, France) after Lugol dying. Steady state was considered to have been achieved for continuous cultures when cell concentration and $A_{680}$ did not vary by more than $10 \%$ for three consecutive days.

\subsection{Assessment of the growth rate-irradiance relationship}

The growth of T-Iso as a function of irradiance was assessed in turbidostat mode in a planartorus photobioreactor. A detailed description of the experimental apparatus is given in Loubiere et al. (2009). Optically clear cultures were run at low cell density $\left(10^{6} \mathrm{cell} \cdot \mathrm{mL}^{-1}\right)$ to avoid self-shading; therefore, incident and averaged irradiance inside the photobioreactor were considered similar. Temperature was set at $27{ }^{\circ} \mathrm{C}$, and $\mathrm{pH}$ maintained at 7.2 by automated injection of $\mathrm{CO}_{2}$. Growth rate was measured as dilution rate (D) at steady state for different levels of irradiance ranging from 10 to $450 \mu \mathrm{mol}$ photon. $\mathrm{m}^{-2} \cdot \mathrm{s}^{-1}$, as measured at the surface of the photobioreactor using a spherical Li-Cor LI193 quantum scalar meter.

A modified Michaëlis-Menten model was used to fit the experimental data (equation 1):

$$
\mu=\mu_{m} *(I-I c) /(K i+I-I c)
$$

equation 1

where $\mu$ is the growth rate $\left(d^{-1}\right), \mu_{m}$ the maximal growth rate $\left(d^{-1}\right), I$ the averaged irradiance inside the culture $\left(\mu \mathrm{mol}\right.$ photon. $\left.\mathrm{m}^{-2} \cdot \mathrm{s}^{-1}\right), I_{c}$ the irradiance at the compensation point $(\mu \mathrm{mol}$ photon. $\mathrm{m}^{-2} \cdot \mathrm{s}^{-1}$ ) and $K_{i}$ the half-saturation irradiance ( $\mu \mathrm{mol}$ photon. $\mathrm{m}^{-2} \cdot \mathrm{s}^{-1}$ ).

Irradiance efficiency for growth rate $E_{\mu}\left(\mu \mathrm{m}^{2}\right.$. $\mu$ mol photon $\left.{ }^{-1}\right)$ was calculated as the ratio of growth rate to irradiance, i.e. the growth rate sustained per irradiance unit. When modeling the growth rate on irradiance curve with equation $1, E_{\mu}$ is then given by equation 2 . It can be demonstrated that the maximum $E_{\mu}^{*}$ can be computed from equation 3 .

$$
E_{\mu}=\mu_{m} *\left(1-\frac{I c}{I}\right)(K i+I-I c)
$$




$$
E_{\mu}^{*}=\mu_{m} * \sqrt{K i-I c} /((K i+\sqrt{K i-I c})(I c+\sqrt{K i-I c})), \quad \text { for } I=I c+\sqrt{K i * I c}
$$

equation 3

We further used the same concept for productivity in a light-limited photobioreactor, with a dilution rate $\mathrm{D}$, and denoted $E_{P}\left(\mathrm{Kg}_{\mathrm{m}} \mathrm{m}^{-1} . \mu \mathrm{mol}\right.$ photon $\left.{ }^{-1}\right)$ the irradiance efficiency for the volumetric productivity (i.e. the ratio of volumetric productivity $\left(D^{*} X\right)$ to incident irradiance). The maximum $E_{P}$ is hereafter denoted $E_{P}^{*}$.

\subsection{Modeling of productivity in a light-limited photobioreactor}

Our modeling approach was based on that previously described in Loubiere et al. (2009) except that, in the present work, we refer to a planar photobioreactor with a $60 \mathrm{~mm}$ optical path length, rather than a tubular photobioreactor. The two-flux formulation of the general theory of radiative transfer was used to compute the irradiance field inside the photobioreator, according to equation 4 and equation 5 :

$$
\begin{array}{cl}
I(z)=2 \cdot I_{0}(1+\alpha) \cdot \exp (\delta \cdot(L-z))-(1-\alpha) \cdot \exp (-\delta \cdot(L-z)) /(1+\alpha)^{2} \cdot \exp (\delta \cdot L)-(1-\alpha)^{2} \cdot \exp (-\delta \cdot L) & \begin{array}{l}
\text { equation } \\
\mathbf{4}
\end{array} \\
\text { With } \alpha=\sqrt{E a /(E a+2 \cdot b \cdot E s)}, \delta=X \cdot \sqrt{E a \cdot(E a+2 \cdot b \cdot E s)} & \text { equation }
\end{array}
$$

where $E_{a}, E_{s}$ and $b$ are T-Iso mass absorption and light scattering coefficients, $b$ the backward scattering fraction, $L$ the optical path length in the photobioreactor, $z$ the depth along the light direction inside the photobioreactor and $I_{0}$ the irradiance at the surface of the photobioreactor.

The optical properties for T-Iso were taken as in Loubière (2009), with $E_{a}=293 \mathrm{~m}^{2} \mathrm{~kg}^{-1}, E_{s}=$ $757 \mathrm{~m}^{2} \mathrm{~kg}^{-1}$ and $b=0.01162$.

The irradiance field, i.e. the distribution of irradiance inside the photobioreactor, was computed along the optical path length and, together with the relationship of growth rate with irradiance, this allowed the local growth rate to be determined for all the positions used for the irradiance field computation. The growth rate was then integrated along the optical path length of the photobioreactor in order to compute the mean specific growth rate that is used to solve equation 6 :

$$
\dot{X}=(\bar{\mu}-D) * X \quad \text { equation } 6
$$

Where $\bar{\mu}$ is the mean specific growth rate $\left(\mathrm{d}^{-1}\right), D$ is dilution rate $\left(\mathrm{d}^{-1}\right), X$ is biomass $(\mathrm{g} \cdot \mathrm{L}-1)$.

The ordinary differential equation is solved by Matlab ODE function with input parameters previously calculated by user $\mathrm{m}$-files Matlab functions. Finally, the photobioreactor productivity was computed at steady state for a set of irradiance and dilution rates.

\subsection{Combined effects of temperature, irradiance and $\mathrm{pH}$ on the growth of Isochrysis affinis galbana}

\subsubsection{Algal strain and maintenance}

Inocula were obtained from continuous cultures so as to start with constant initial physiological conditions by running a chemostat culture in a $2 \mathrm{~L}$-photobioreactor device, previously described in Bougaran et al. (2003). T-Iso was grown at $27 \pm 0.5{ }^{\circ} \mathrm{C}$ under 
continuous light at $110 \mu \mathrm{mol}$ photon. $\mathrm{m}^{-2} \cdot \mathrm{s}^{-1}$, as measured with a spherical Li-Cor LI193 quantum scalar meter. Aeration was maintained at $0.20 \pm 0.05 \mathrm{~L}$. $\min ^{-1}$ and $\mathrm{pH}$ regulated at $7.20 \pm 0.05$ with automatic $\mathrm{CO}_{2}$ injection. Impeller speed was $120 \mathrm{rpm}$ and dilution rate 0.15 $\mathrm{d}^{-1}$.

\subsection{2. $2^{3^{*}}$ Experimental design}

The experiments consisted in a $2^{3^{*}}$ central composite design involving three environmental factors : temperature, $\mathrm{pH}$ and irradiance. Within a single set of experiments, where different combinations of the previous factors were tested simultaneously, this approach allowed to assess the optimal conditions for growth rate, as well as the effects on growth rate of putative interactions between factors.

Seventeen experiments were needed to incorporate this $2^{3^{*}}$ central composite design (Lundstedt et al., 1998). To estimate the second order quadratic component of the relationship between a factor and the dependent variable (i.e. maximum growth rate $\mu_{m}$ ), five levels were used for the respective factors. It can be shown that by adding so-called starpoints to the simple (cube) 2-level factorial design points, a rotatable design can be achieved. Three center point replicates were added to evaluate experimental variance. The distance between star points and center points was calculated using the axial distance $\alpha=$ 1.682. The general quadratic model fitted to the data is given in equation 7 .

$\mu_{m}=\beta_{0}+\beta_{1} \mathrm{X}_{1}+\beta_{2} \mathrm{X}_{2}+\beta_{3} \mathrm{X}_{3}+\beta_{12} \mathrm{X}_{1} \mathrm{X}_{2}+\beta_{13} \mathrm{X}_{1} \mathrm{X}_{3}+\beta_{23} \mathrm{X}_{2} \mathrm{X}_{3}+\beta_{11} \mathrm{X}_{1}^{2}+\beta_{22} \mathrm{X}_{2}^{2}+\beta_{33} \mathrm{X}_{3}^{2}+\varepsilon$

equation 7

where $\beta_{\mathrm{i}}, \beta_{\mathrm{ij}}$, and $\beta_{\mathrm{ii}}$ are model coefficients, $X_{i}$ the main effect for the factor $i, X_{i j}$ the interaction between the factors $i$ and $j, X_{i}^{2}$ the quadratic effect of the factor $i$ and $\varepsilon$ the residual error. Here, $X_{1}$ was chosen for temperature, $X_{2}$ for irradiance and $X_{3}$ for $\mathrm{pH}$.

\subsubsection{Experimental device}

The experimental culture device TIP (Figure 1) was specifically developed to do batch culture experiments under precise growth conditions according to the $2^{3^{*}}$ central composite design. The apparatus was made up of seventeen $250 \mathrm{~mL}$-plastic photobioreactors located inside an incubator (Newbrunswick) that maintained ambient temperature below the lowest desired condition. Each photobioreactor was thermo-regulated by a heater connected to a temperature sensor, and its $\mathrm{pH}$ was controlled by $\mathrm{CO}_{2}$ injections. Each photobioreactor was therefore fitted to a pH electrode (Mettler-Toledo) and a gas injection line controlled by a 3way solenoid valve. Continuous aeration was maintained until $\mathrm{CO}_{2}$ injection was required. Light was supplied through the transparent bottom of each photobioreactor by a single xenon lamp through an optical fibre harness (FORETEC, France). In order to reach the desired irradiance level, each photobioreactor was fitted with the appropriate number of fibres. Cultures were mixed by automatic shaking. A specific Labview based supervisor program (National instruments) was designed to manage temperature and $\mathrm{pH}$ sensors calibration as well as their continuous control. For each factor, the achievable range is given in the Table 1.

\subsubsection{Experimental procedure}

Prior to inoculation, the 17 photobioreactors were sterilized with a solution of $0.5 \%$ peroxyacetic acid for $20 \mathrm{~min}$. The photobioreactors were then inoculated with $150 \mathrm{~mL}$ of an optically clear phytoplankton culture $\left(X_{0}=6 \times 10^{5}\right.$ cell. $\left.\mathrm{mL}^{-1}\right)$, allowing a low culture depth (5 $\mathrm{cm})$ so as to limit self-shading between cells. Culture conditions were randomised within the experimental device (Table 2). Cultures were sampled twice a day and cellular concentration was assessed as described above. Temperature and $\mathrm{pH}$ were tested daily in the 17 photobioreactors in order to prevent measurement drift. Evaporation was also checked at the 
end of the experiment and never exceeded $3 \%$ of the initial volume. It was therefore not considered further.

\section{7. $N$ and $P$ requirements for Isochrysis affinis galbana}

The effects of nitrate $(N)$ and phosphate $(P)$ limitation were studied in 2L-photobioreactor chemostats sterilized with a $0.5 \%$ peroxyacetate solution. Temperature was set at $27 \pm 1{ }^{\circ} \mathrm{C}$, $\mathrm{pH}$ maintained at 7.2 and incident light flux at $130 \mu \mathrm{mol}$ photon. $\mathrm{m}^{-2} \cdot \mathrm{s}^{-1}$. The photobioreactors were inoculated with phytoplankton at $5 \times 10^{5}$ cell. $\mathrm{mL}^{-1}$ cell density and run with different dilution rates in chemostat conditions. Some cultures were carried out in $\mathrm{N}$-limited Walne medium at dilution rates ranging from 0.09 to $1.08 \mathrm{~d}^{-1}$, while others were performed under $P$ limited Walne medium at dilution rates ranging from 0.29 to $0.95 \mathrm{~d}^{-1}$. For the $N$-limited medium, $N$ and $P$ supply were 58 and $102 \mu \mathrm{M}$, respectively $(N: P=0.57)$, while for the $P$ limited medium, these were 573 and $5 \mu \mathrm{M}$, respectively $(N: P=115)$. The cultures were aerated $\left(0.2 \mathrm{~L}\right.$. $\left.\mathrm{min}^{-1}\right)$ and the impeller speed was set at $120 \mathrm{rpm}$. Cellular concentration was assessed as described above. Steady state was considered to have been achieved when cell density and optical density did not vary by more than $10 \%$ for three consecutive days.

At steady state, residual phosphate and nitrate concentration was measured daily with a DX500 ionic chromatography system (DIONEX) equipped with an AS9-HC column. Since dissolved organic phosphorus was verified to account for less than $8 \%$ of total dissolved phosphorus, the cell phosphorus quota was calculated from the difference between inflow and residual phosphorus concentration, using equation 8, as described in Bougaran et al., (2010).

$$
Q_{P}=(P-P) / X
$$

equation 8

where $Q_{P}$ is the cell quota (fmol $P$. cell ${ }^{-1}$ ), $X$ the cellular concentration (cell. $L^{-1}$ ), $P i$ the inflow phosphorus concentration (fmol $P . L^{-1}$ ) and $P$ the residual phosphorus concentration in the bioreactor (fmol P. $L^{-1}$ ).

Cell nitrogen and carbon quota $\left(Q_{N}\right.$ and $\left.Q_{C}\right)$ were also determined daily for each steady state, using a CHN elemental analyzer (EAGER 300, Thermo Scientific). Samples were filtered through precombusted Whatmann GF/C glassfilters and dried at $70{ }^{\circ} \mathrm{C}$ for $48 \mathrm{~h}$. All cell quotas were computed from the mean of the cellular concentration throughout the steady state period.

Finally, at steady state, $N$ and $P$ uptake $\left(\rho_{N}\right.$ and $\left.\rho_{p}\right)$ were computed from the cell quota (Bougaran et al., 2010), according to equation 9,

$$
\rho_{s}=\mu \cdot Q_{s}
$$

equation 9

where $\rho_{s}$ is the uptake of nutrient $S\left(\right.$ fmol.cell $\left.{ }^{-1} \cdot d^{-1}\right), \mu$ the specific growth rate $\left(\mathrm{d}^{-1}\right)$ and $Q_{s}$ the cell quota $\left(\right.$ fmol.cell $\left.{ }^{-1}\right)$ for nutrient $S$.

The critical ratio was computed as the ratio of $Q_{N}$, under $N$-limited growth, to $Q_{P}$, under $P$ limited growth, at a given growth rate. The ratio was calculated using both cell-based $\left(R_{C}\right)$ and carbon-based quotas $\left(R_{C}^{\prime}\right)$. As $N$ and $P$ quotas could not be measured for the same dilution rates, the critical ratio was computed from the regression model fitted to the experimental data rather than directly from the data. 


\subsection{Statistical and mathematical analysis}

Linear and non linear least square regression and fit analyses were performed with Matlab software. The correlation coefficient, $p$-value and number of observations are given for each regression analysis.

The specific growth rate $(\mu)$ was computed with Matlab software, by fitting a cubic spline (smooth piecewise-polynomial function) to the experimental data and further deriving the obtained function. Re-integration of the resulting curve of $\mu$ according to time was compared to the experimental growth curve in order to confirm the growth rate kinetic.

Statgraphics Plus software was used for both the experimental design and the statistical analysis based on response surface estimation.

\section{Results}

\subsection{Determination of growth performances as a function of irradiance}

The 28 steady states achieved enabled the turbidostat experiment to precisely assess the growth rate - irradiance curve for T-Iso, as shown in Figure 2a. As no photoinhibition occurred up to $450 \mu \mathrm{mol}$ photon. $\mathrm{m}^{-2} \cdot \mathrm{s}^{-1}$, a modified Michaelis-Menten model (equation 1) was fitted to the data and resulted in the following set of parameters: $\mu_{m}=2.2 \mathrm{~d}^{-1}, I_{c}=11 \mu \mathrm{mol}$ photon. $\mathrm{m}^{-2} \cdot \mathrm{s}^{-1}$ and $K_{i}=37 \mu \mathrm{mol}$ photon $\cdot \mathrm{m}^{-2} \cdot \mathrm{s}^{-1}$ (Figure 2a).

Due to the high number of data in the initial region of the growth rate on irradiance curve, computation of irradiance efficiency $E_{\mu}$ according to irradiance made it clear that $E_{\mu}$ sharply increased for very low irradiance, reached a maximum for an irradiance of $31 \mu \mathrm{mol}$ photon. $\mathrm{m}^{-2} \cdot \mathrm{s}^{-1}$ and decreased any further increase in irradiance (Figure 2b). We used the same concept for the volumetric productivity $E_{P}$ at steady state. Model simulation for the volumetric productivity in the flat panel photobioreactor (with a $60 \mathrm{~mm}$ optical path length) showed that, whatever the steady-state culture density, qualitative trends for $E_{P}$ were similar to that for $E_{\mu}$ computed for optically clear cultures, although the maximum $E_{P}^{*}$ was achieved for a higher incident irradiance, as cultures were no longer optically clear (Figure 3a). Furthermore, as dilution rate increased, the maximum $E_{P}^{\star}$ was achieved for higher irradiances (Figure $3 b$ ). Results for the flat panel photobioreactor with the $60 \mathrm{~mm}$ optical path length predicted an absolute maximum for $E_{P}^{*}\left(1.210^{-8} \mathrm{~kg} \cdot \mathrm{m}^{-1} \cdot \mu \mathrm{mol}\right.$ photon $\left.{ }^{-1}\right)$ for a given irradiance $(70 \mu \mathrm{mol}$ photon. $\left.\mathrm{m}^{-2} \cdot \mathrm{s}^{-1}\right)$ and dilution rate $\left(0.7 \mathrm{~d}^{-1}\right)$.

\subsection{Combined effects of temperature, irradiance and $\mathrm{pH}$ on growth}

A significant correlation was found between cell concentration and $A_{680}\left(r^{2}=0.97, p\right.$-value < $\left.10^{-7}, \mathrm{n}=114\right)$. $A_{680}$ was, therefore, used to calculate specific growth rate (Table 3 ), allowing higher sampling frequency. In this experiment, the maximal growth rate was achieved under $780 \mu \mathrm{mol}$ photon. $\mathrm{m}^{-2} \cdot \mathrm{s}^{-1}$ for irradiance, $30{ }^{\circ} \mathrm{C}$ for temperature and $6.8 \mathrm{for} \mathrm{pH}$. The resulting model explained $84 \%$ of the observed variability and the lack of fit was not significant ( $p$ value $=0.188$ ); associated parameters are given in Table 4 .

A significant positive linear effect of temperature ( $p$-value $<0.05)$ was observed: the higher the temperature the faster the growth within the experimental domain. Quadratic effects for the three factors were also significant and are illustrated in Figure 4(a, c). In addition, significant interactions ( $\mathrm{p}$-value $<0.05)$ could be observed between $\mathrm{pH}$ and temperature, and between $\mathrm{pH}$ and irradiance, (Figure $4 \mathrm{~b}$ ). 


\section{3. $\quad N$ and $P$ requirement for Isochrysis affinis galbana}

Cellular quotas for carbon, nitrogen and phosphorus are summarized in Table 5. Under both $N$ - and $P$-limited conditions, $Q_{C}$ exhibited a concave curvature with growth rate, the curvature being more pronounced for $P$-limited cultures. Indeed, our results highlighted that under $\mathrm{N}$ limited growth, $Q_{C}$ varied from $700 \mathrm{fmol}$ C.cell ${ }^{-1}$ (at low dilution rate) to $530 \mathrm{fmol}^{-}$.cell ${ }^{-1}$ (at $D$ $=0.8 \mathrm{~d}^{-1}$ ). Under $P$-limited growth, $Q_{C}$ varied from 885 to $500 \mathrm{fmol}^{-}$.cell ${ }^{-1}$ in the same dilution rate range. $Q_{N}$ increased linearly from 49 to $65 \mathrm{fmol} \mathrm{N}$. cell ${ }^{-1}$ for dilution rates ranging from 0.09 to $1.08 \mathrm{~d}^{-1}\left(\mathrm{r}^{2} \approx 0.46, \mathrm{p}\right.$-value $\left.<10^{-4}, \mathrm{n}=35\right)$. A significant linear correlation was also found between $Q_{P}$ and growth rate, although $Q_{P}$ appeared to be rather stable around $1 \mathrm{fmol}$ $P$. cell ${ }^{-1}\left(r^{2}=0.59, p\right.$-value $\left.<10^{-4}, \mathrm{n}=29\right)$. $N$ and $P$ carbon-based quotas $\left(q_{N}\right.$ and $\left.q_{P}\right)$ were also computed as a function of dilution rate (Table 5) and gave similar trends to cell-based quotas $\left(r^{2} \approx 0.69, p\right.$-value $<10^{-4}, n=35$ and $r^{2} \approx 0.57, p$-value $<10^{-4}, n=29$, respectively).

A significant linear correlation was also found between $N$ uptake, under $N$-limited conditions, and growth rate $\left(r^{2}=0.98, p\right.$-value $\left.<10^{-4}, \mathrm{n}=42\right)$, as well as between $P$ uptake, under $P$ limited conditions, and growth rate $\left(r^{2}=0.93, p\right.$-value $\left.<10^{-4}, n=20\right)$. According to Figure 5 , $N$ uptake, for $N$-limited growth, increased from 5 to $70 \mathrm{fmol} . \mathrm{cell}^{-1} \cdot \mathrm{d}^{-1}$ and $P$ uptake, for $P$ limited growth, from 0.3 to $0.8 \mathrm{fmol}^{-\mathrm{cell}^{-1}} \cdot \mathrm{d}^{-1}$ as dilution rate increased from 0.09 to $1.1 \mathrm{~d}^{-1}$ and 0.29 to $0.8 \mathrm{~d}^{-1}$, respectively.

The critical ratios for $N$ and $P$ cell-based $(R c)$ or carbon-based $\left(R c^{\prime}\right)$ quotas as a function of dilution rate are given in Figure 6. Rc was rather stable and extended from 51 to 54 for the dilution range tested, whereas $R c^{\prime}$ decreased from 68 to 50 .

\section{Discussion}

\subsection{Effect of irradiance on Isochrysis affinis galbana growth}

The turbidostat experiment lasted 12 months and involved 28 successive steady states on different optically clear cultures. It provided comprehensive information and an accurate picture of the relationship between growth and irradiance for T-Iso. Although growth saturation was rapidly achieved for irradiance levels higher than $200 \mu \mathrm{mol}$ photon. $\mathrm{m}^{-2} \cdot \mathrm{s}^{-1}$, no photoinhibition could be recorded up to $400 \mu \mathrm{mol}$ photon. $\mathrm{m}^{-2} \cdot \mathrm{s}^{-1}$. These results are in agreement with those of Sukenik and Wahnon (1991) and Tzovenis et al. (2003), where growth saturation occurred when irradiance was higher than 300 and $200 \mu \mathrm{mol}$ photon. $\mathrm{m}^{-2} \cdot \mathrm{s}^{-1}$, respectively, without any photoinhibition up to 500 and $460 \mu \mathrm{mol}$ photon. $\mathrm{m}^{-2} \cdot \mathrm{s}^{-1}$, respectively.

Discrepancies between our results and the literature were noted for the maximum specific growth rate reported for T-Iso. In this study, a maximum specific growth rate of $2.2 \mathrm{~d}^{-1}$ was recorded, while Sukenik and Wahnon (1991) and Tzovenis et al. (2003) reported maximum specific growth rates of 1.25 and $1.2 \mathrm{~d}^{-1}$, respectively. These differences could be related to the prevailing conditions in the different experiments, with different geometry of the culture vessels, light sources or culture media (F/2 for Sukenik and Wahnon (1991); Walne in the present study) and more probably uncontrolled or higher pH: Tzovenis et al. (2003) did not specify whether $\mathrm{pH}$ was controlled or not in their experiment and Sukenik and Wahnon (1991) used a slightly higher $\mathrm{pH}$ in their experiment (7.8) than was used in the present work (7.2). Indeed, the TIP experiment highlighted that $\mathrm{pH}$ substantially affects growth. This effect was already mentioned by Bartual and Galvez (2002) who reported a reduced specific growth rate at high $\mathrm{pH}$ under subsaturating irradiance. 
In the literature, reports on compensation irradiance (Ic) for microalgae are scarce because the number of observations in the light-limited initial slope region is often limited and this precludes its accurate computation. To our knowledge, the present study is the first report on $I c$ for T-Iso growth rate. Although $I c$ is species dependent and geometry of the culture vessels may vary among studies, Falkowski et al. (1985) reported values of 16, 17 and 23 umol photon. $\mathrm{m}^{-2} \cdot \mathrm{s}^{-1}$ for the growth of Isochrysis galbana, Prorocentrum micans and Thalassiosira weissflogii, respectively, all of which are only slightly higher than the value found here for T-Iso $\left(11 \mu \mathrm{mol}\right.$ photon. $\left.\mathrm{m}^{-2} \cdot \mathrm{s}^{-1}\right)$.

In the present work, two different methods were used to assess the relationship between irradiance and growth rate. The TIP experiment achieved a high saturation irradiance (700 $\mu \mathrm{mol}$ photon. $\mathrm{m}^{-2} \cdot \mathrm{s}^{-1}$ ) that could hardly be compared with the results of the turbidostat experiment where no photoinhibition occurred in the range $0-400 \mu \mathrm{mol}$ photon. $\mathrm{m}^{-2} \cdot \mathrm{s}^{-1}$ under investigation. The two experiments revealed discrepancies for growth rate, especially at low irradiance. Because of its mathematical formulation, it should be stressed that the quadratic model associated with the factorial design cannot correctly predict a consistent compensation irradiance value. Additionally, the design of a $2^{3^{*}}$ factorial approach involves only two experiments for the extreme conditions outside the experimental domain (the socalled star points) and, therefore, does not allow an accurate prediction for the response under the lowest and the highest irradiances tested. It follows that, while the factorial design approach is a suitable method to describe overall trends, it can hardly be used to assess the growth rate on irradiance curve accurately.

Commonly, irradiance efficiency is calculated as the initial slope of the growth or photosynthesis rate on irradiance curve. This conventional computation depicts the increase of growth (or photosynthesis) for a given irradiance increase. Here we proposed to compute the irradiance efficiency, $E_{\mu}$, for growth as the ratio of growth rate to irradiance. This ratio made it clear that irradiance efficiency for growth is maximal for incident irradiance even lower than the half-saturation constant, and decreases for higher irradiance. From a mathematical point of view, it can be seen that the occurrence of a maximum $E_{\mu}$ is related to the offset for the compensation irradiance. As photosynthesis exhibits a similar offset, it follows that net photosynthesis rate normalized to chlorophyll $a$ is subjected to a similar maximum irradiance efficiency too. Indeed, Kishino et al. (1986) used a similar ratio, derived from the photosynthetic rate, for investigating the light utilization efficiency by phytoplankton in the sea. The authors reported similar trends for the light utilization efficiency. On the basis of their data, we could compute a maximum in the range $34-37 \mu \mathrm{mol}$ photon. $\mathrm{m}^{-2} \cdot \mathrm{s}^{-1}$, which is very similar to $E_{\mu}^{*}$ reported here for the turbidostat experiment.

Our modeling approach for productivity demonstrated a maximum irradiance efficiency for productivity, $E_{P}^{*}$, which resulted in an absolute optimal set for irradiance and dilution rate for a given photobioreactor geometry. This result has important implications for commercial production of microalgae (discussed below). For the sake of simplicity, our modeling approach assumed that the cell pigment content was constant, i.e. pigment acclimation to irradiance was not taken into account. It is still unclear how pigment acclimation could affect $E_{\mu}$ and $E_{P}$ in dense cultures and experimental data are needed to further examine this issue. Nevertheless, Molina Grima et al. (1997) reported a maximum Isochrysis galbana growth yield in a high density chemostat under 820 and $1630 \mu \mathrm{mol}$ photon. $\mathrm{m}^{-2} \cdot \mathrm{s}^{-1}$. These results, in turn, confirm the occurrence of a maximum $E_{\mu}^{*}$ and the qualitative results of our modeling approach.

\subsection{Effect of $\mathrm{pH}$ and temperature on growth}

The model resulting from the factorial design assigned $\mathrm{pH}$ as the most important factor influencing T-Iso growth rate and predicted a significant quadratic effect with an optimal value at 6.8. Although very few datasets are available for the effect of $\mathrm{pH}$ on microalgae in general and especially T-Iso, Kaplan et al. (1986) pointed out the same quadratic effect for 
this species, although they reported that a lower $\mathrm{pH}$ (6.0) was required for high growth. Despite the discrepancy between the two absolute values, the optimal $\mathrm{pH}$ was lower than that of natural seawater in both cases. However, our results support the 7.0 to 8.0 range for $\mathrm{pH}$ used in other studies, such as Brown et al. (1993) at pH 7.4-7.8, or Sukenik and Wahnon (1991) at pH 7.8. In contrast, Abu Rezq et al. (1999) did not find any significant influence of $\mathrm{pH}$ on T-Iso growth and cell density. Nevertheless, it should be noted that the TIP model did not either predict any substantial growth rate difference for the $\mathrm{pH}$ values $(6.75$ and 7.25$)$ these authors tested.

As shown in Figure 4, temperature controls growth through a positive linear effect, with an additional significant quadratic effect. This result means that the higher the temperature the higher the growth rate in the range of temperature tested. Nevertheless, the highest temperature tested $\left(30^{\circ} \mathrm{C}\right)$ markedly reduced growth rate. This effect was confirmed by Kaplan et al. (1986) and Claquin et al. (2008) for T-Iso. In addition, we found an optimal temperature of $30{ }^{\circ} \mathrm{C}$, which is in agreement with the results of Renaud et al. (2002) and Claquin et al. (2008), who reported optimal temperature for T-Iso to be $27-30^{\circ} \mathrm{C}$ and $30.7^{\circ} \mathrm{C}$, respectively. In contrast, the present result is slightly higher than the $26{ }^{\circ} \mathrm{C}$ and $24-26{ }^{\circ} \mathrm{C}$ and $27^{\circ} \mathrm{C}$ reported by Saoudi-Helis et al. (1994), Abu Rezq et al. (1999) and Kaplan et al. (1986), respectively. A number of different optimal values are, therefore, reported in literature for the same species. However, these resulted from monofactorial experiments run under different $\mathrm{pH}$ conditions from 6.75 to 8.6 .

Beyond the main effects on growth for each factor, the experimental factorial design found significant interactions between temperature and $\mathrm{pH}$, and between $\mathrm{pH}$ and irradiance. The former interaction shows that temperature weakly affected growth under the highest $\mathrm{pH}$ conditions tested (i.e. $\mathrm{pH}>8.0$ ), as $\mathrm{CO}_{2}$ availability limited growth rate . In contrast, under lower $\mathrm{pH}$, low temperature (i.e. $\mathrm{T}<19^{\circ} \mathrm{C}$ ) dramatically depressed growth rate, while higher temperature resulted in increased growth rate. Such an interaction has already been reported for Nannochloropsis oculata (Spolaore et al., 2006). Variation of $\mathrm{CO}_{2}$ fixation as a function of temperature could be the key to this interaction. Indeed, Anning et al. (2001) recorded that the rate of carbon fixation was impaired at low temperatures and suggested that it could be related to a decrease in photosynthetic enzymes. Geider (1987) also demonstrated that temperature favored carboxylase activity of ribulose-1,5-biphosphate carboxylase/oxygenase (RubisCO), resulting in higher $\mathrm{CO}_{2}$ fixation.

An irradiance-pH interaction was also found to be significant for T-Iso. This interaction highlighted that low $\mathrm{pH}$ and high irradiance improved growth rate, in relation with a concomitant increase in photochemical energy and carbon availability. Under high $\mathrm{pH}$, the growth response was only little affected by irradiance and this observation could account for growth rate limitation by inorganic carbon availability. Bartual and Galvez (2002) investigated the effects of $\mathrm{pH}$ and DIC availability on Phaeodactylum tricornutum growth under restricted or saturated light conditions: the authors reported an altered growth response for lightlimited culture when $\mathrm{CO}_{2}$ availabilty was low and $\mathrm{pH}$ was high. Furthermore, Maberly (1985) emphasized an increase for $I c$ under low $\mathrm{CO}_{2}$ availability (i.e. under high $\mathrm{pH}$ ). It is also well documented that $\mathrm{CO}_{2}$ assimilation is reduced under low irradiance (Beardall et al. , 1998). However it remains unclear, here, why low irradiance combined with low $\mathrm{pH}$ conditions resulted in a dramatically depressed growth rate.

It is worth noting that, in situations where irradiance or temperature were not optimal, low $\mathrm{pH}$ led to a sharper decrease for growth rate. Accordingly, our results stress the necessity of $\mathrm{pH}$ control in high productivity T-Iso cultures.

An interaction could have been expected between irradiance and temperature. Indeed, different parameters of the photosynthesis-irradiance curve are affected by temperature, as are the saturation point $E_{k}$ (Hammer et al., 2002), light-saturated photosynthesis rate, 
maintenance respiration (Geider et al., 1998) and photosynthetic efficiency (Claquin et al., 2008). However, we did not observe any significant interaction between these factors for TIso growth rate, in agreement with the results of Spolaore et al. (2006) on Nannochloropsis oculata.

An important point of these findings is that interactions may have a greater effect on growth rate than the direct effects of each factor. Comparison of Figure $4 a$ and $b$ clearly shows that the interaction between temperature and $\mathrm{pH}$ explains about twice the variation due to the direct effect for temperature or $\mathrm{pH}$. The same observation also holds for the interaction between $\mathrm{pH}$ and irradiance. Interactions can, therefore, explain the differences for optimal growth conditions reported for T-Iso in the literature, of most studies were conducted with a monofactorial approach. Such interactions between irradiance, $\mathrm{CO}_{2}$ concentration and temperature with photosynthesis have already been pointed out by Maberly (1985), who emphasized the necessity of taking all factors into account when studying the effect of one of these factors on photosynthesis".

\subsection{Nitrogen and phosphorus requirements}

Our results showed that $N$ and $P$ cellular uptake increased linearly with dilution rate under $N$ and $P$ limitation, respectively. Elrifi and Turpin (1985) recorded similar trends and rates for $N$ cellular uptake in Selenastrum minutum (30 and 75 versus 35 and $70 \mathrm{fmol} N \cdot$ cell $^{-1} \cdot \mathrm{d}^{-1}$ in this study, for $\mu=0.6 \mathrm{~d}^{-1}$ and $\mu=1.1 \mathrm{~d}^{-1}$, respectively), while $P$ cellular uptake was almost three times lower in the case of $S$. minutum $\left(0.6\right.$ and 2.5 versus 0.22 and $1 \mathrm{fmol} P . \mathrm{cell}^{-1} . \mathrm{d}^{-1}$ in this study, for $\mu=0.3 \mathrm{~d}^{-1}$ and $\mu=0.8 \mathrm{~d}^{-1}$, respectively).

In contrast to the uptake rate, cellular quota showed different trends depending on the limiting nutrient. Under $N$ limitation, $N$ quota (on both cell and carbon basis) increased with growth rate, but $P$ quota remained rather stable under $P$ limitation, whatever the dilution rate in the range tested. Again, these results are in agreement with the previous study of Elrifi and Turpin (1985) on $S$. minutum, where $Q_{N}$ increased from 30 to $70 \mathrm{fmol} N$.cell ${ }^{-1}$ with dilution rate (ranging from 0 to $\left.1.1 \mathrm{~d}^{-1}\right)$, while $Q_{P}$ was stable for low dilution rate $\left(0\right.$ to $\left.0.5 \mathrm{~d}^{-1}\right)$. Similar trends were also reported for Pavolva lutheri (Terry et al., 1985).

Computation for the critical $N: P$ ratio, where the transition from one limitation to another takes place, is useful for studies dealing with the design of a balanced medium. Cell volume variation has been shown to have significant implications for the computation of critical $N: P$ ratio (Terry et al., 1980; Flynn, 2002), while cell volume can be estimated on the basis of the carbon-cellular quota $\left(Q_{C}\right)$ for different taxonomic groups (Menden-Deuer and Lessard, 2000). In our chemostat experiment, $Q_{C}$ was shown to vary with growth rate. Under the assumption that the relationship between $Q_{C}$ and cell volume remains valid under different nutrient limitations, cell volume may vary by a factor of 1.3 to 1.8, depending on growth and the limiting nutrient._Since $R c$ (cell-based critical $N: P$ ratio) refers to cell-based quota, computation for $R c$ can be biased by substantial changes in cell size with changes in limiting nutrients. Conversely, computation for R'c refers to carbon-based quota and therefore precludes cell size changes issues. This resulted, here, in different trends for $R c$ and $R$ 'c. As already pointed out by Terry (1980), R'c provides a more useful tool for generalization about relative requirements for nutrients. It is, therefore, best to consider the carbon-based quota rather than the cell-based quota in order to compute critical $N: P$ ratio. In this study, $R$ 'c was found to be a decreasing function of growth rate, varying from about 70 to 50 . Such a decreasing trend of $R^{\prime} C$ with growth highlighted that $P$ requirement increased faster than the $N$ requirement (Rhee, 1978; Terry, 1980; Elrifi and Turpin, 1985; Agren, 2004). Although R'C is known to be species specific, our results are consistent with the values reported by Terry (1980) for Pavlova lutheri. 
When the range for $R c$ reported here for T-Iso is compared with the composition of culture media currently used in laboratories and shellfish hatcheries, discrepancies are clearly shown between the relative requirements and the supply for $N$ and $P$. Indeed, the Walne medium $N: P$ ratio is only 7 while this is 28 for the $\mathrm{f} / 2$ medium. The Walne medium, therefore, appears to be highly $N$-limited for T-Iso growth, while the f/2 medium is less unbalanced, although it is also $N$-limited, whatever the growth rate. Hence, it is clear that optimization for the commercial production of T-Iso would require the design and use of a new medium, with a $N: P$ ratio specifically adapted to this species.

The scope of our analysis is, however, subject to some limitations related to light. In the present study, nutrient-limited chemostats were maintained under continuous light with an incident irradiance of $130 \mu \mathrm{mol}$ photon. $\mathrm{m}^{-2} \cdot \mathrm{s}^{-1}$. The light dependency for the $\mathrm{C}: \mathrm{Chl}$ ratio (Geider, 1987) would directly affect the C:N ratio and would, therefore, affect $R c$ if different irradiances were used (Wynne and Rhee, 1986). Further studies are therefore needed to accurately assess the $N$ and $P$ requirement under varying irradiance.

\subsection{Implications for the optimization of Isochrysis affinis galbana production in continuous culture}

The present study focused on the environmental factors that can be readily controlled in artificially illuminated photobioreactors in order to produce continuous large scale cultures in molluscs hatcheries with an adapted culture device as presented by Loubière et al. (2009). In this type of culture system, irradiance is probably one of the most complex factors to control inside a photobioreactor because it is subjected to absorption and self-shading, resulting in a light gradient along the optical path. Its effect on photobioreactor productivity has been widely studied elsewhere, giving rise to several modeling approaches (Molina Grima et al., 1996; Loubiere et al., 2009). To our knowledge, studies aiming at productivity optimization in photobioreactors have so far focused on a volumetric or per-surface basis. However, these approaches would only support energetic and economic optimization if $E_{\mu}$ was constant, whatever the irradiance. Our analysis strongly suggests that economic optimization does not match up with mass productivity optimization. As light constitutes a significant proportion of the production cost (Benson et al., 2009), its supply should be adapted depending on the photobioreactor geometry and dilution rate. Our analysis further highlighted that, for a given photobioreactor, an economic optimum set for incident irradiance and dilution rate can be achieved. A striking conclusion from our study is that the economic optimization for artificially illuminated photobioreactors requires a much lower irradiance than does volumetric optimization.

Nutrient supply is another important issue, as it significantly contributes to production costs and can result in eutrophication problems in the environment around hatcheries in cases of unbalanced and excess supply. The present study showed that, for commonly used culture media, the $N: P$ ratio should be increased to match the requirements of $T$-Iso under continuous culture. The $N: P$ ratio has also shown to be a decreasing function of the growth rate (i.e. dilution rate at steady state). It follows that, once the economic optimum is set for irradiance and dilution rate, the $N: P$ input ratio can readily be adjusted to its optimum.

Finally, temperature and $\mathrm{pH}$ were found to greatly affect T-Iso growth and control loops are accordingly required in order to maintain the optimum value for both factors throughout the culture period. Additionally, our analysis of interactions between temperature, irradiance and $\mathrm{pH}$ revealed that irradiance did not interact with temperature. Hence, temperature can be set to its optimal value, i.e. $30{ }^{\circ} \mathrm{C}$, regardless of the incident irradiance. Conversely, significant $\mathrm{pH}$ - temperature and $\mathrm{pH}$ - irradiance interactions were found; so $\mathrm{pH}$ should not be set without taking into account temperature and irradiance prevailing in the photobioreactor. The growth model, resulting from the factorial design experiment, provides a helpful tool to set $\mathrm{pH}$ at a level that will optimize growth. 
We illustrate and summarize the results of our optimization process considering the planar photobioreactor, with a $60 \mathrm{~mm}$ optical depth, we used for modeling irradiance. In this particular case, in order to optimize $E_{P}$, the dilution rate should be set to $0.7 \mathrm{~d}^{-1}$, with a 70 $\mu \mathrm{mol}$ photon. $\mathrm{m}^{-2} . \mathrm{s}^{-1}$ incident irradiance. Given the dilution rate, the $N: P$ supply ratio should be 50 for a balanced input of $N$ and $P$ that would prevent $N$ or $P$ washing-out. Temperature should then be set at $30^{\circ} \mathrm{C}$ and $\mathrm{pH}$ at 7.5 in order to complete the economic optimization for continuous production of T-Iso.

Finally, as a proof of concept, this optimization procedure will be sequentially tested in the 120-L photobioreactor described in Loubiere et al. (2009) and currently implemented in a French mollusk hatchery.

\section{Conclusion}

In this paper we presented a set of experiments aiming to optimize the continuous culture of Isochrysis affinis galbana under controlled conditions. We first assessed the relationship between light and growth rate and pointed out that an optimum irradiance efficiency for growth $\left(E_{\mu}\right)$, occurred at irradiance much lower than the saturating level. Our modeling approach for irradiance efficiency optimization highlighted that volumetric or surface productivity optimization does not result in an optimal productivity on an economic point of view. The factorial design experiment made possible to assess the optimal temperature and $\mathrm{pH}$ conditions for the growth of Isochrysis affinis galbana. In agreement with (Maberly, 1985), our analysis particularly highlighted the necessity of taking the interaction between factors into account. To avoid imbalanced nutrient supply and excess nutrient wash-out from the culture, we also assessed the critical $N: P$ ratio for a range of growth rate. Finally, we proposed a practical guide for aquaculturists to achieve economic optimization for indoor continuous culture of Isochrysis affinis galbana.

\section{Acknowledgments}

The authors thank Sebastien Lefebvre for the helpful discussions and comments on the manuscript.

\section{References}

Abu Rezq, T. S., Al Musallam, L., Al Shimmari, J., Dias, P., (1999). Optimum production conditions for different high-quality marine algae. Hydrobiologia 403 (0), 97-107.

Agren, G. I., (2004). The C:N:P stoichiometry of autotrophs : theory and observations. Ecology Letters 7 (3), 185-191.

Alonso, D. L., Belarbi, E. H., Fernandez Sevilla, J. M., Rodriguez Ruiz, J., Grima, E. M., (2000). Acyl lipid composition variation related to culture age and nitrogen concentration in continuous culture of the microalgea Phaeodactylum tricornutum. Phytochemistry 54 (5), 461-471.

Anning, T., Harris, G., Geider, R. J., (2001). Thermal acclimation in the marine diatom Chaetoceros calcitrans (Bacillariophyceae). European Journal of Phycology 36 (3), 233-241.

Bartual, A., Galvez, L. A., (2002). Growth and biochemical composition of the diatom Phaeodactylum tricornutum at different $\mathrm{pH}$ and inorganic carbon levels under saturating and subsaturating light regimes. Botanica Marina 45 (6), 491-501. 
Beardall, J., Johnston, A., Raven, J. A., (1998). Environmental regulation of $\mathrm{CO}_{2}$ concentrating mechanisms in microalgae. Canadian Journal of Botany 76 (6), 1010-1017.

Benemann, J. R., (1992). Microalgae aquaculture feeds. Journal of applied Phycology 4 (3), 233-245.

Benson, B. C., Gutierrez-Wing, M. T., Rusch, K. A., (2009). Optimization of the lighting system for a Hydraulically Integrated Serial Turbidostat Algal Reactor (HISTAR): Economic implications. Aquacultural Engineering 40 (1), 45-53.

Berges, J. A., Varela, D. E., Harrison, P. J., (2002). Effects of temperature on growth rate, cell composition and nitrogen metabolism in the marine diatom Thalassiosira pseudonana (Bacillariophyceae). Marine Ecology Progress Series 225, 139-146.

Boeing, P., (2000). Larval Feed Alternatives. Global Aquaculture Advocate 3 (1), 48-50.

Borowitzka, M. A., (1997). Microalgae for aquaculture : opportunities and constraints. Journal of applied Phycology 9 (5), 393-401.

Bougaran, G., Bernard, O., Sciandra, A., (2010). Modeling continuous cultures of microalgae colimited by nitrogen and phosphorus. Journal of Theoretical Biology 265 (3), 443-454.

Bougaran, G., Le Dean, L., Lukomska, E., Kaas, R., Baron, R., (2003). Transient initial phase in continuous culture of Isochrysis galbana affinis Tahiti. Aquatic Living Resources 16 (4), 389-394.

Brown, M. R. (2002). Nutritional value and use of microalgae in aquaculture. Avances en Nutrición Acuícola VI. Memorias del VI Simposium Internacional de Nutrición Acuícola. N. Simoes. Cancún, Quintana Roo, México., 281-292.

Brown, M. R., Garland, C. D., Jeffrey, S. W., Jameson, I. D., Leroi, J.-M., (1993). The gross and amino acid compositions of batch and semi-continuous cultures of Isochrysis sp. (clone T.ISO), Pavlova lutheri and Nannochloropsis oculata. Journal of applied Phycology 5 (3), 285-296.

Claquin, P., Probert, I., Lefebvre, S., Veron, B., (2008). Effects of temperature on photosynthetic parameters and TEP production in eight species of marine microalgae. Aquatic Microbial Ecology 51 (1), 1-11.

Coutteau, P., Castell, J. D., Ackman, R. G., Sorgeloos, P., (1996). The use of lipid emulsions as carriers for essential fatty acids in bivalves: a test case with juvenile Placopecten magellanicus. Journal of Shellfish Research 15 (2), 259-264.

Coutteau, P., Sorgeloos, P., (1992). The use of algal substitutes and the requirement for live algae in the hatchery and nursery rearing of bivalve molluscs: an international survey. Journal of Shellfish Research 11 (2), 467-476.

Douillet, P. A., Langdon, C. J., (1994). Use of a probiotic for the culture of larvae of the Pacific Oyster (Crassostrea gigas Thunberg). Aquaculture 119 (1), 25-40.

Duerr, E. O., Molnar, A., Sato, V., (1998). Cultured microalgae as aquaculture feeds. Journal of Marine Biotechnology 6 (2), 65-70.

Elrifi, I. R., Turpin, D. H., (1985). Steady-state luxury consumption and the concept of optimum nutrient ratios : a study with phosphate and nitrate limited Selenastrum minutum (Chlorophyta). Journal of Phycology 21 (4), 592-602.

Fabregas, J., Herrero, C., Cabezas, B., Abalde, J., (1986). Biomass production and biochemical composition in mass cultures of the marine microalga Isochrysis galbana Parke at varying nutrient concentrations. Aquaculture 53 (2), 101-113.

Fabregas, J., Patino, M., ArredondoVega, B. O., Tobar, J. L., Otero, A., (1995). Renewal rate and nutrient concentration as tools to modify productivity and biochemical composition of cyclostat cultures of the marine microalga Dunaliella tertiolecta. Applied Microbiology and Biotechnology 44 (3-4), 287-292.

Falkowski, P. G., Dubinsky, Z., Wyman, K., (1985). Growth-irradiance relationships in phytoplankton. Limnology and Oceanography 30 (2), 311-321.

Flynn, K. J., (2002). How critical is the critical N:P ratio ? Journal of Phycology 38 (5), 961 970.

G., F. P., (1985). Growth-irradiance relationships in phytoplancton. Limnol. Oceanogr. 30 (2), 311-321. 
Geider, R. J., (1987). Light ant temperature dependence of the carbon to chlorophyll a ratio in microalgae and cyanobacteria: implications for physiology and growth of phytoplankton. New phytologist 106 (1), 1-34.

Geider, R. J., Maclntyre, H. L., Kana, T. M., (1998). A dynamic regulatory model of phytoplanktonic acclimation to light, nutrients, and temperature. Limnology and oceanography 43 (4), 679-694.

Hammer, A., Schumann, R., Schubert, H., (2002). Light and temperature acclimation of Rhodomonas salina (Cryptophyceae): photosynthetic performance. Aquatic Microbial Ecology 29 (3), 287-296.

Kaplan, D., Cohen, Z., Abeliovich, A., (1986). Optimal growth conditions for Isochrysis galbana. Biomass 9 (1), 37-48.

Kishino, M., Okami, N., Takahashi, M., Ichimura, S., (1986). Light utilization efficiency and quantum yield of phytoplankton in a thermally stratified sea. Limnology and Oceanography 31 (3), 557-566.

Knauer, J., Southgate, P. C., (1997). Evaluation of microencapsulated squid oil as a substitute for live microalgae fed to Pacific oyster (Crassostrea gigas) Spat. Journal of Shellfish Research 16 (1), 137-141.

Knauer, J., Southgate, P. C., (1997). Growth and fatty acid composition of Pacific oyster (Crassostrea gigas) spat fed a microalga and microcapsules containing varying amounts of eicosapentaenoic and docosahexaenoic acid. Journal of Shellfish Research 16 (2), 447-453.

Loubiere, K., Olivo, E., Bougaran, G., Pruvost, J., Robert, R., Legrand, J., (2009). A new photobioreactor for continuous microalgal production in hatcheries based on external loop airlift and swirling flow. Biotechnology and Bioengineering 102 (1), 132-147.

Lundstedt, T. r., Seifert, E., Abramo , L., Thelin, B., Nyström, A., Pettersen, J., Bergman, R., (1998). Experimental design and optimization. Chemometrics and Intelligent Laboratory Systems 42 (1-2), 3-40.

Maberly, S. C., (1985). Photosynthesis by Fontinalis antipyretica : I. Interaction between photon irradiance, concentration of carbon dioxide and temperature. New Phytologist 100 (2), 127-140.

McCausland, M. A., Brown, M. R., Barett, S. M., Diemar, J. A., Heasman, M. P., (1999). Evaluation of live microalgae and microalgal pastes as supplementary food for juvenile Pacific oysters (Crassostrea gigas). Aquaculture 174 (3-4), 323-342.

Menden-Deuer, S., Lessard, E. J., (2000). Carbon to volume relationships for dinoflagellates, diatoms, and other protist plankton. Limnology and Oceanography 45 (3), 569-579.

Molina Grima, E., Fernandez Reiriz, M. J., Sanchez Perez, J. A., Garcia Camacho, F., (1996). A study on simultaneous photolimitation and photoinhibition in dense microalgal cultures taking into account incident and averaged irradiances. Journal of Biotechnology 45 (1), 59-69.

Molina Grima, E., Garcia Camacho, F., Sanchez Perez, J. A., Acien Fernandez, F. G., Fernandez Sevilla, J. M., (1997). Growth yield determination in a chemostat culture of the marine microalga Isochrysis galbana. Journal of applied Phycology 8 (6), 529-534.

Nell, J. A., (2002). Farming triploid oysters. Aquaculture 210, 69-88.

Pulz, O., Gross, W., (2004). Valuable products from biotechnology of microalgae. Applied Microbiology and Biotechnology 65, 635-648.

Renaud, S. M., Thinh, L. V., Lambrinidis, G., Parry, D. L., (2002). Effect of temperature on growth, chemical composition and fatty acid composition of tropical Australian microalgae grown in batch cultures. Aquaculture 211 (1-4), 195-214.

Rhee, G. Y., (1978). Effects of N:P atomic ratios and nitrate limitation on algal growth, cell composition, and nitrate uptake. Limnology and Oceanography 23 (1), 10-24.

Rico-Villa, B., Woerther, P., Mingant, C., Lepiver, D., Pouvreau, S., Hamon, M., Robert, R., (2008). A flow-through rearing system for ecophysiological studies of Pacific oyster Crassostrea gigas larvae. Aquaculture 282 (1-4), 54-60.

Robert, R., Gerard, A., (1999). Bivalve hatchery technology : the current situation for the Pacific oyster Crassostrea gigas and the scallop Pecten maximus in France. Aquatic Living Resources 12 (2), 121-130. 
Robert, R., Parisi, G., Rodolfi, L., Poli, B. M., Tredici, M. R., (2001). Use of fresh and preserved Tetraselmis suecica for feeding Crassostrea gigas larvae. Aquaculture $192(2-4)$, 333-346.

Robert, R., Trintignac, P., (1997). Substitutes for live microalgae in mariculture : a review. Aquatic Living Resources 10, 315-327.

Rosenberg, J. N., Oyler, G. A., Wilkinson, L., Betenbaugh, M. J., (2008). A green light for engineered algae : redirecting metabolism to fuel a biotechnology revolution. Current Opinion in Biotechnology 19 (5), 430-436.

Sanchez, S., Martinez, M. E., Espinola, F., (2000). Biomass production and biochemical variability of the marine microalga Isochrysis galbana in relation to culture medium. Biochemical Engineering Journal 6 (1), 13-18.

Saoudi-Helis, L., Dubacq, J. P., Marty, Y., Samain, J. F., Gudin, C., (1994). Influence of growth rate on pigment and lipid composition of the microalga Isochrysis aff.galbana clone T.iso. Journal of applied Phycology 6 (3), 315-322.

Spolaore, P., Joannis-Cassan, C., Duran, E., Isambert, A., (2006). Optimization of Nannochloropsis oculata growth using the response surface method. Journal of Chemical Technology and Biotechnology 81 (6), 1049-1056.

Sukenik, A., Wahnon, R., (1991). Biochemical quality of marine unicellular algae with special emphasis on lipid composition : I. Isochrysis galbana. Aquaculture 97 (1), 61-72.

Taraldsvik, M., Myklestad, S. M., (2000). The effect of pH on growth rate, biochemical composition and extracellular carbohydrate production of the marine diatom Skeletonema costatum. European Journal of Phycology 35 (2), 189-194.

Terry, K. L., (1980). Nitrogen and phosphorus requirements of Pavlova lutheri in continuous culture. Botanica Marina 23, 757-764.

Terry, K. L., Laws, E. A., Burns, D. J., (1985). Growth rate variation in the N:P requirement ratio of phytoplankton. Journal of Phycology 21, 323-329.

Tzovenis, I., De Pauw, N., Sorgeloos, P., (2003). Optimisation of T-Iso biomass production rich in essential fatty acids : I. Effect of different light regimes on growth and biomass production. Aquaculture 216 (1-4), 203-222.

Walne, P. R., (1966). Experiments in the large scale culture ol th larvae of Ostrea edulis. L. Fish. Invest. Ministr. Agric. Fish. Food (GB) Ser. II XXV (4), 53.

Wynne, D., Rhee, G. Y., (1986). Effects of light intensity and quality on the relative $N$ and $P$ requirement (the optimum N:P ratio) of marine planktonic algae. Journal of Plankton Research 8 (1), 91-103.

\section{Tables}

Table 1. Achievable factor ranges in the TIP device.

\begin{tabular}{lll}
\hline Factor & minimum & maximum \\
\hline Temperature $\left({ }^{\circ} \mathrm{C}\right)$ & 10.0 & 45.0 \\
$\mathrm{pH}$ & 5.0 & 10.0 \\
Irradiance $(\mu \mathrm{mol}$ photon.m-2.s-1) & 50 & 1070 \\
\hline
\end{tabular}


Table 2: Factor levels in the TIP experiment, where $\alpha$ is the axial distance between star points and the center of the experimental domain.

\begin{tabular}{lccccc}
\hline Factor level & $-\alpha$ & -1 & 0 & +1 & $+\alpha$ \\
\hline Temperature $\left({ }^{\circ} \mathrm{C}\right)$ & 15.3 & 19 & 24.5 & 30 & 33.7 \\
Irradiance $\left(\mu \mathrm{mol}\right.$ photon. $\left.\mathrm{m}^{-2} \cdot \mathrm{s}^{-1}\right)$ & 50 & 257 & 560 & 863 & 1070 \\
$\mathrm{pH}$ & 6.0 & 6.5 & 7.3 & 8.0 & 8.5 \\
\hline
\end{tabular}

Table 3: Specific growth rate computed for the different conditions in the factorial design experiment.

\begin{tabular}{cccc}
\hline Temperature $\left({ }^{\circ} \mathrm{C}\right)$ & $\mathrm{pH}$ & $\mathrm{I}\left(\mu \mathrm{mol} . \mathrm{m}^{-2} . \mathrm{s}^{-1}\right)$ & $\mu\left(\mathrm{d}^{-1}\right)$ \\
\hline 19.0 & 8.0 & 863 & 0.41 \\
19.0 & 8.0 & 257 & 0.51 \\
19.0 & 6.5 & 257 & 0.06 \\
24.5 & 7.3 & 560 & 0.69 \\
30.0 & 6.5 & 863 & 0.71 \\
24.5 & 7.3 & 560 & 0.78 \\
15.3 & 7.3 & 560 & 0.21 \\
24.5 & 7.3 & 560 & 0.65 \\
30.0 & 6.5 & 257 & 0.51 \\
30.0 & 8.0 & 257 & 0.51 \\
33.7 & 7.3 & 560 & 0.60 \\
30.0 & 8.0 & 863 & 0.16 \\
24.5 & 6.0 & 560 & 0.15 \\
24.5 & 8.5 & 560 & 0.43 \\
19.0 & 6.5 & 863 & 0.30 \\
24.5 & 7.3 & 50 & 0.18 \\
24.5 & 7.3 & 1070 & 0.68 \\
\hline
\end{tabular}

Table 4: Regression coefficients for the growth model where $\square$ vis the model error and where the subscript 1 is for temperature, 2 for $\mathrm{pH}$ and 3 for irradiance.

\begin{tabular}{cc}
\hline Notations & Terms \\
\hline$\beta_{0}$ & -23.2684 \\
$\beta_{1}$ & 0.418603 \\
$\beta_{2}$ & 4.70589 \\
$\beta_{3}$ & 0.00483128 \\
$\beta_{12}$ & $-0.033 \square 364$ \\
$\beta_{23}$ & -0.000489549 \\
$\beta_{11}$ & -0.00322216 \\
$\beta_{22}$ & -0.245566 \\
$\beta_{33}$ & $-9.65407 .10^{-7}$ \\
\hline
\end{tabular}


Table 5: Cell and carbon based quota ( \pm standard deviation) on dilution rate for the $N$ - and $P$ limited conditions.

\begin{tabular}{|c|c|c|c|c|c|c|}
\hline & $\mathrm{D}$ & $Q_{N}$ & $Q_{P}$ & $Q_{C}$ & $q_{N}$ & $q_{P}$ \\
\hline & $\mathrm{d}^{-1}$ & fmol.cell $^{-1}$ & & & mol.mol C ${ }^{-1}$ & \\
\hline \multirow[t]{6}{*}{ N-limited } & 0.09 & $48.56 \pm 1.06$ & $9.12 \pm 0.21$ & $704.74 \pm 3.49$ & $0.0691 \pm 0.0046$ & $0.1790 \pm 0.0400$ \\
\hline & 0.19 & $42.61 \pm 8.92$ & $15.73 \pm 0.93$ & $593.90 \pm 2.25$ & $0.0825 \pm 0.0032$ & $0.2815 \pm 0.0273$ \\
\hline & 0.35 & $63.11 \pm 1.74$ & $10.85 \pm 0.71$ & $608.16 \pm 2.29$ & $0.0104 \pm 0.0018$ & $0.1834 \pm 0.0173$ \\
\hline & 0.56 & $53.55 \pm 4.59$ & $13.03 \pm 0.79$ & $559.80 \pm 2.56$ & $0.0938 \pm 0.0958$ & $0.2247 \pm 0.0307$ \\
\hline & 0.80 & $62.05 \pm 3.28$ & $5.99 \pm 1.76$ & $530.59 \pm 2.38$ & $0.1165 \pm 0.0022$ & $0.0890 \pm 0.0331$ \\
\hline & 1.08 & $65.15 \pm 1.86$ & nd & $553.72 \pm 2.15$ & $0.1161 \pm 0.0044$ & $0.0712 \pm 0.0887$ \\
\hline \multirow[t]{4}{*}{ P-limited } & 0.29 & $79.13 \pm 2.09$ & $0.98 *$ & $885.94 \pm 4.51$ & $0.0899 \pm 0.0047$ & $0.0191 \pm 0.0028$ \\
\hline & 0.58 & $55.84 \pm 4.53$ & $1.01 *$ & $544.77 \pm 1.90$ & $0.1025 \pm 0.0072$ & $0.0136 \pm 0.0002$ \\
\hline & 0.80 & $56.51 \pm 3.45$ & $1.12 *$ & $500.06 \pm 4.52$ & $0.1105 \pm 0.0074$ & $0.0180 \pm 0.0005$ \\
\hline & 0.95 & $72.66 \pm 2.81$ & nd & $539.12 \pm 3.43$ & $0.1350 \pm 0.0047$ & nd \\
\hline
\end{tabular}

* Residual P was undetectable and standard deviation could not be computed.

\section{Figures}

Fig. 1

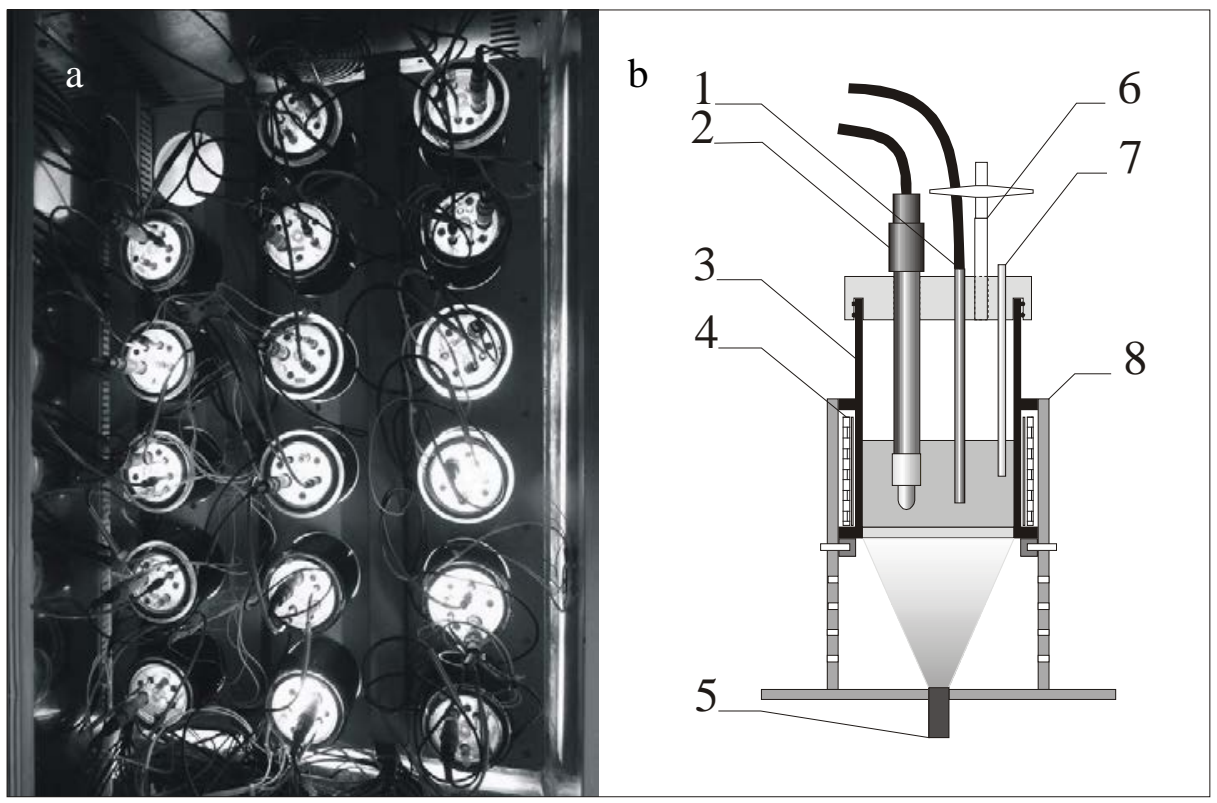

Figure 1: a) Experimental culture device (TIP) made up of seventeen $250 \mathrm{~mL}$ photobioreactors located inside an incubator. b) Schematic view of a TIP photobioreactor. 1- temperature probe ; 2- pH probe ; 3- photobioreactor ; 4- heating jacket ; 5- optical fibre ; 6- air outlet ; 7- air bubbling / CO2 inlet ; 8holder. 
Fig.2
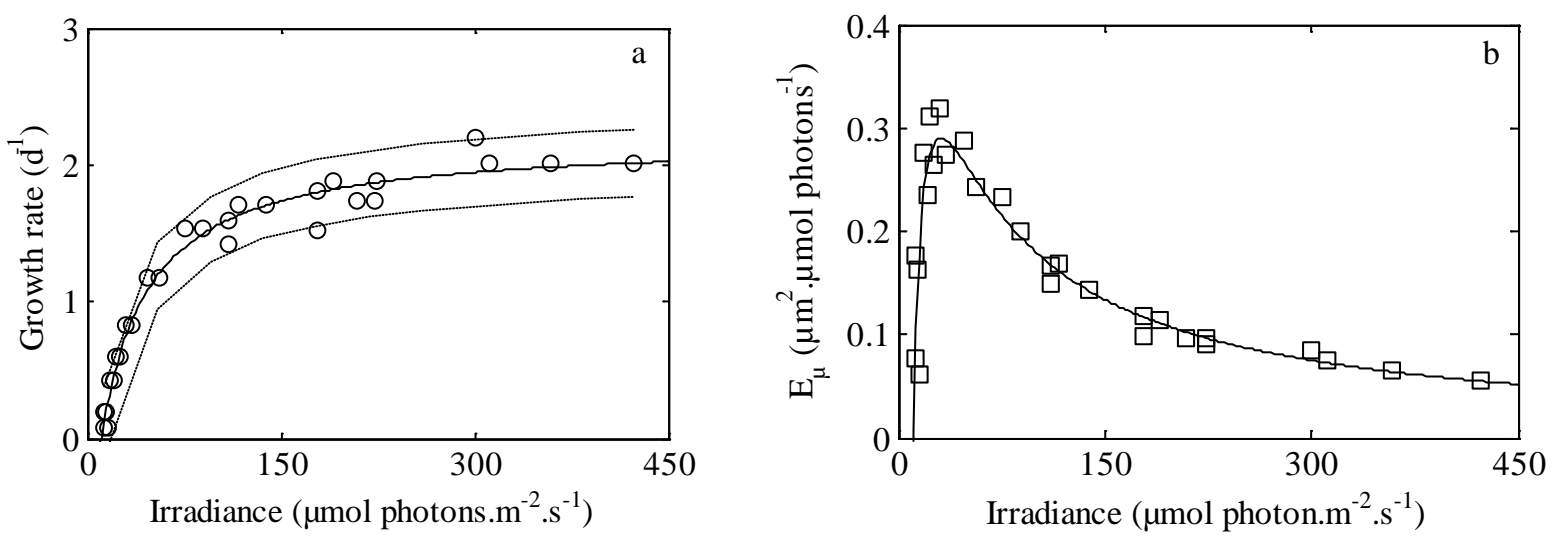

Figure 2: a) Growth rate as a function of irradiance: experimental data (open circles) were fitted with equation 1 (solid line; $r^{2}=0.97$ ). The lower and upper dotted lines represent the $95 \%$ confidence boundaries. b) Irradiance efficiency for growth rate $(E \mu)$ on irradiance for optically clear cultures. 
Fig. 3
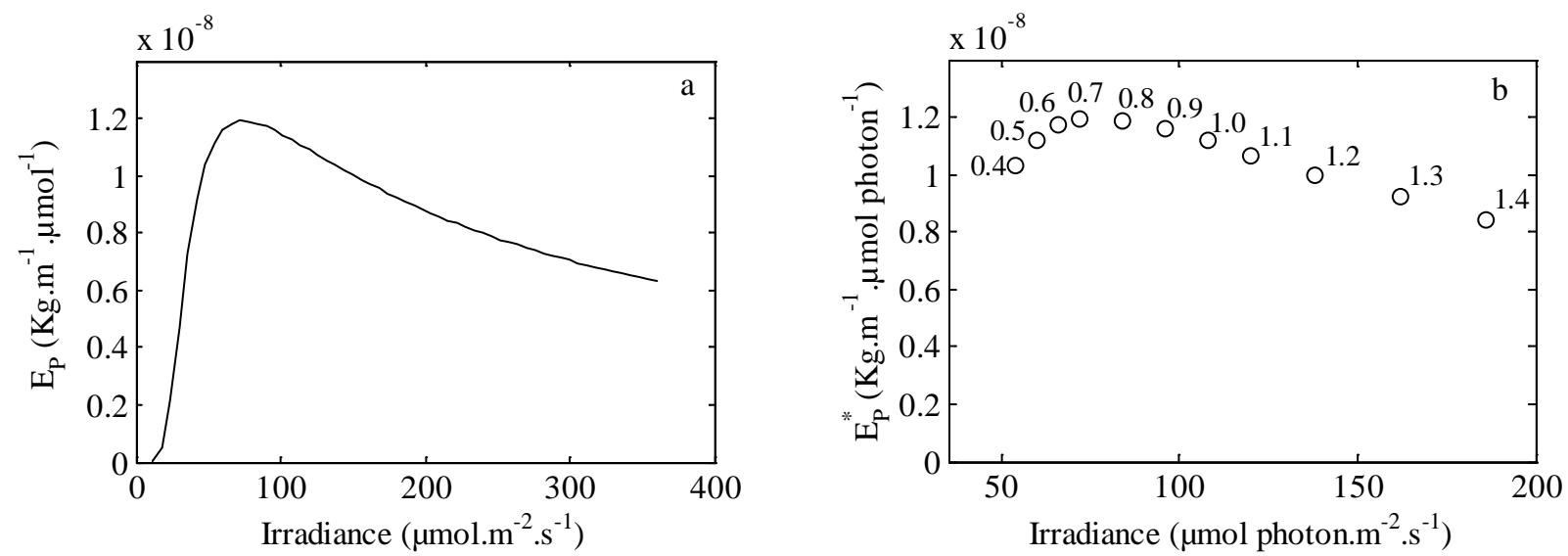

Figure 3: a) Simulation of irradiance efficiency for productivity $\left(E_{P}\right)$ on irradiance, computed at steady state and for dilution rate $D=0.7 \mathrm{~d}^{-1} ;$ b) simulation of maximum $E_{P}^{\star}$ on irradiance for dilution rate ranging from 0.4 to $1.4 \mathrm{~d}^{-1}$; the numbers indicate the associated dilution rate. 
Fig.4

$\mathrm{a}$
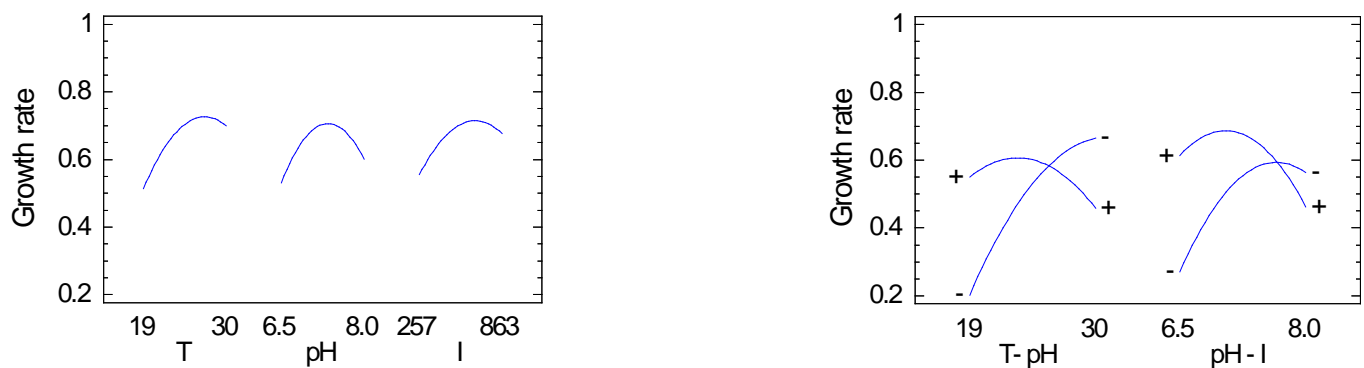

C
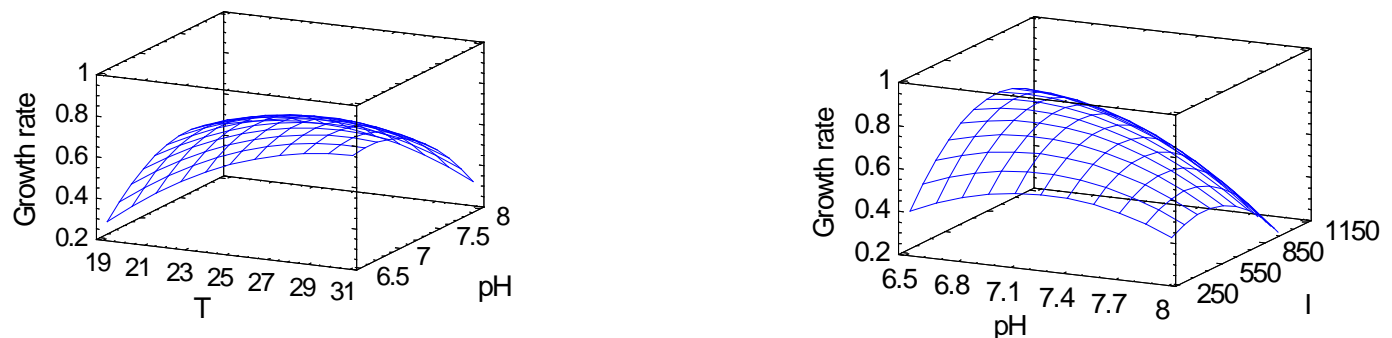

Figure 4: a) Standardized effects for irradiance, temperature and $\mathrm{pH}$ on growth rate; $\mathrm{b}$ ) interaction plots for the growth rate, where the (+) and (-) curves illustrate the growth response for the high and low level for the second factor; c) and d) surface plots of the modeled growth rate $\left(d^{-1}\right)$ for two of the three factors, when the third one is set to its optimal level: $\mathrm{c}$ ) temperature on $\mathrm{pH}$ and d) $\mathrm{pH}$ on irradiance. $T=$ temperature $\left({ }^{\circ} \mathrm{C}\right) ; \mathrm{I}=$ irradiance $\left(\mu \mathrm{mol}\right.$ photon $\left.\cdot \mathrm{m}^{-2} \cdot \mathrm{s}^{-1}\right)$. 
Fig.5
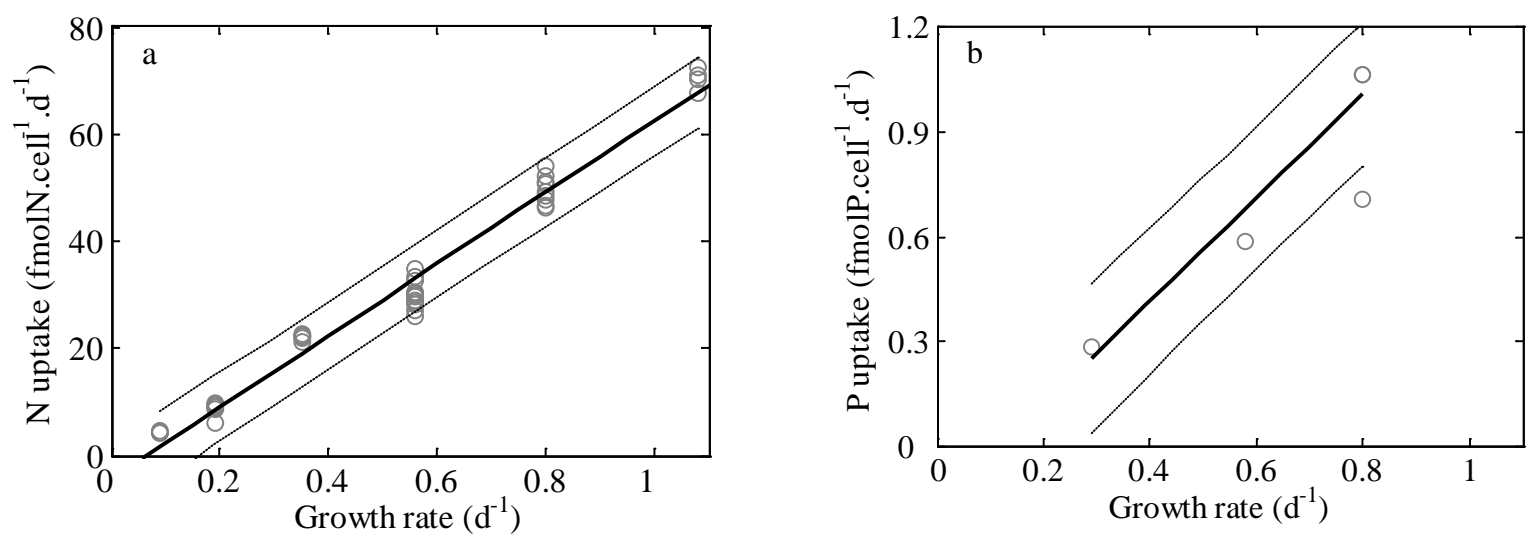

Figure 5: Nitrogen and phosphorus uptake for T-Iso grown under $N$-limited and $P$-limited conditions respectively. 
Fig. 6

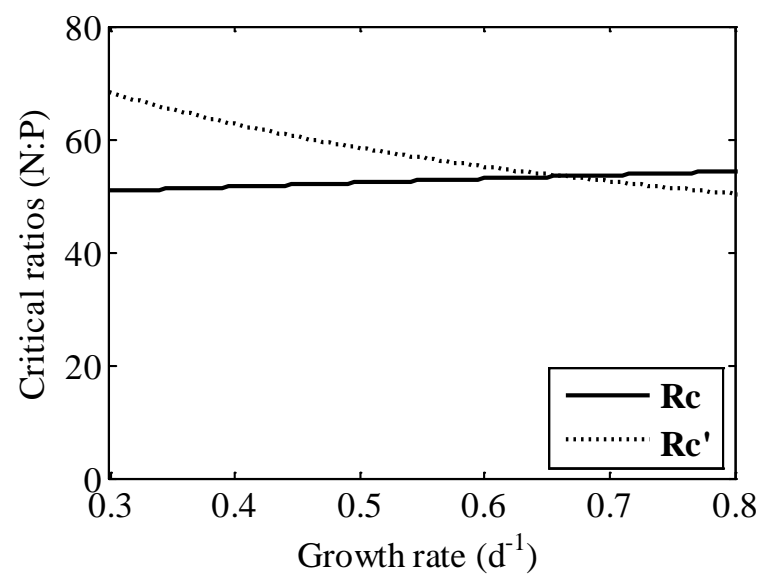

Figure 6: Critical ratio on a per cell $\left(R c=Q_{N}: Q_{P}\right)$ and a per-carbon basis $\left(R^{\prime} c=q_{N}: q_{P}\right)$ 